\title{
Study on Index System of Safety Risk Assessment for City Gas Industry
}

\author{
Hui LYU' Wei Zhu' ${ }^{1}$ Yafei Wang ${ }^{1}$ Qian Wang ${ }^{2}$ \\ ${ }^{1}$ Beijing Research Center of Urban System Engineering, Beijing 100035, China; \\ ${ }^{2}$ Safety and Environmental Engineering of School, Capital University of Economics and \\ Business, Beijing, 100070, China
}

\begin{abstract}
In view of the current urban gas risk assessment research most focused on one aspect of the system, such as gas pipe network, gate station and indoor gas pipeline specialized research, lacking a complete urban gas transmission and distribution system risk assessment classification method. Based on the research findings of safety risk assessment, as the gas pipeline as the research object, starting from the inherent risk and dynamic risk of the assessment object, through the "human object - environment - management" system analysis, gas risk probability index system and consequences severity index system were established. At Last the weight of each index was determined by AHP, which laid the foundation for the classification of gas industry risk assessment and provided the standardization of gas industry risk assessment classification method reference.
\end{abstract}

\section{Keywords}

Gas pipeline; Safety risk; Risk assessment; Index system

\section{城市燃气管线安全风险评估指标体系研 究}

\author{
吕慧 ${ }^{1}$ 朱伟 $^{1}$ 王亚飞 ${ }^{1}$ 王倩 ${ }^{2}$ \\ ${ }^{1}$ 北京城市系统工程研究中心, 北京, 100035 , 中国 \\ 2 首都经济贸易大学 安全科学与环境工程学院, 北京, 100070, 中国
}

摘要：针对目前城市燃气风险评估方面的研究主要集中在系统的某一个方面, 缺乏对完整的 城市燃气输配系统的风险评估分级方法的探讨的问题，在安全风险评估研究的基础上，以燃 气管线为研究对象，从评估对象的固有风险和动态风险入手，通过 “人-物-环-管” 系统分 析, 建立了燃气风险可能性指标体系和后果严重性指标体系, 并采用层次分析法确定了各指 标的权重, 为燃气行业风险评估分级奠定基础, 对燃气行业风险评估分级方法的标准化提供 参考。

关键词：燃气管线; 安全风险; 风险评估; 指标体系 


\section{0 引言}

随着城市建设的发展和人口密度 的增加,作为城市主要能源之一的城市 燃气,人们对其安全运行的安全性,提出 了更高的要求 ${ }^{[1]}$ 。这些易燃、易爆的流 体一旦泄漏、爆炸不但会造成人员伤 亡和经济损失，甚至造成不良的社会 和环境影响 [2]。通过开展风险评估工 作，可以指导如何采取必要的措施以 消除或减少安全隐患,降低一定时期内 事故发生的频率和严重性,从而提高系 统的抗风险能力。因此，如何寻找一 种途径和方法, 有效地评估城市燃气 管线风险状况，根据现有管线风险水 平, 遵循突出重点、分级监管的原 则, 采取有针对性的监管措施, 是一 个值得研究的课题。

\section{1 燃气管线安全风险分析}

燃气管线风险的一个部位发生事 故, 不但会造成经济损失和人员伤 亡, 而且有可能使整个系统发生崩 溃, 从而造成正常运行秩序的混乱。

安全风险是指生产安全事故发生 的可能性及其可能造成后果严重性的 组合。安全风险评估包括风险可能性 分析、风险后果严重性分析以及确定 风险等级等环节 [3]。风险评估方法包括 情景分析法、德尔菲法、头脑风暴 法, 概率论方法, 事件树、事故树, 计算机模拟、层次分析法、Bow-tie 法、瑞士奶酪模型。

目前，国内外燃气管网风险评估 方法研究主要包括定性和定量两个研 究方向。由于定性和定量方法的计算 结果存在较好的相似性, 因此在实际 的工程应用中, 可以根据评估目的和 数据情况选取适当的方法进行风险评 估 ${ }^{[4]}$ 。由于燃气数据和信息可获取性较 为困难, 本文主要从影响燃气管线风
险评估结果的可能性和后果指标入 手, 借助指标体系进行定性风险评 估。

本文所建立的指标体系由可能性 指标和事故后果指标以及各指标的权 重共同组成。指标应能客观地描述特 定的燃气评估对象的风险状况 ${ }^{[5]}$, 指标 体系的建立应遵循系统性、专业性、 综合性、时效性等原则。此外, 由于 燃气管网的复杂性, 风险分析指标体 系的建立还应遵循全面性与代表性相 结合、定性分析与定量分析结合、科 学性与可操作性相结合、动态性与静 态性相结合的原则 ${ }^{[6]}$, 充分体现综合性 指标、单项要素指标、动态指标、静 态指标、定量指标、定性指标等。

\section{2 指标体系的构建思路}

（1）固有风险和动态风险。

一般来说, 影响风险的因素大致 可以分为可变因素和非可变因素两 类。企业的综合风险由固有风险和动 态风险构成 ${ }^{[7]}$ 。固有风险主要由评估对 象自身性质决定, 一般不可人为改 变; 动态风险指通过人的努力可以改 变的因素。

以企业为例, 固有风险体现了其 基本风险水平, 主要包括危险化学品 物质、周边环境等因素, 动态风险反 映了企业安全生产管理及绩效的水 平, 主要包括安全基础管理和安全动 态管理等因素。

以燃气管线为例, 固有风险的大 小与燃气管网的运行、施工建造情况 有关, 包括管输流量、压力、管道直 径、最小埋深、管壁厚度和使用年限 等。动态风险主要指燃气管网投入使 用后, 受到的外界风险因素的影响, 比如外部破坏、腐蚀、地质活动、运 行维护失效等。

（2）“人-物-环-管”系统。 
通常认为生产安全系统是 “人、 物、环、管”的构成。根据安全系统 思维分别对燃气门站、管道和小区进 行风险识别, 进而构建门站、管线和 小区的可能性指标。

以燃气管线为例, 可能性指标中 “人的因素” 包括工作人员的安全意 识、安全技能、违章操作等, “物的 因素”包括介质的安全以及相关设备 设施的安全，“环的因素”包括土 壤、腐蚀、第三方破坏等，“管理因 素”包括安全管理制度、现场安全检 查等。

（3）北京市安全风险评估经验。

《北京市安全风险评估规范（试 行）》中也列出了安全风险引发事故 或突发事件的可能性指标和后果严重 性指标。安全风险发生可能性指标包 括历史发生概率、现场管理水平和风 险承受能力。其中, 对历史发生概率 的评估是根据该风险过去 $\mathrm{N}$ 年发生此 类突发事件的次数) 频率得出, 对现 场管理水平的评估借鉴了安全生产标 准化评审分值; 后果严重性指标主要 考虑了人、经济、社会和保障四个领 域。

\section{3 城市燃气管线风险评估指标体系}

基于指标体系的构建思路, 笔者 以燃气管线为研究对象, 建立了燃气 风险可能性指标体系和后果严重性指 标体系。

（1）风险可能性指标体系。

燃气管线风险可能性指标体系:包 括 5 个一级指标和 21 个二级指标。燃 气管线风险可能性的一级指标包括自 身特征、环境因素、安全基础管理、 安全现场管理、人的因素; 二级指标 包括历史发生概率、管道材质及敷设 方式、压力级别、管道年限、燃气管 道沿线地区等级、防火距离、地理位 置、土壤环境、安全生产责任制、规
章制度、安全档案记录、警示标志、 管道腐蚀、第三方服务、沿线巡检、 运行控制、应急救援、管理人员、一 线员工、附近居民等。

(2) 风险后果指标体系。

风险后果性指标是指对人员、经 济、环境、政治和社会的影响。本文 在确定后果型指标时, 通过借鉴美国 肯特法风险评估 ${ }^{[8]}$, 同时结合北京市燃 气集团风险评估工作的实践经验, 最 终确定了包含 2 个一级指标和 6 个二 级指标的燃气风险后果指标体系。

风险后果型的一级指标包括泄露 危害和事故影响, 二级指标包括介质 危险性、环境危险性、人口密度、财 产分布、周边敏感目标影响、基础设 施破坏或中断等。

\section{4 权重的确定}

\section{1 可能性指标权重的确定}

层次分析法, 即 The Analytic Hierarchy Process (AHP), 是 70 年代中 期提出的具有定性化、系统化、层次 化等特点的分析方法。这种方法是一 种简便、灵活而又实用的多准则决策 方法, 通过量化决策者的经验和知 识, 将决策对象按照逻辑关系进行分 层和剖析, 并根据专家的经验性建议 确定指标间的权重。层次分析法多适 用于目标结构复杂且缺乏数据的情 况, 自提出以来, 在多个行业的决策 问题得到广泛的应用 ${ }^{[9-10]}$ 。

层次分析法 (AHP) 解决问题的 基本步骤包括专家打分、矩阵归一 化、一致性检验、得出权重 ${ }^{[11]}$ 。为了 获得指标权重，笔者采用层次分析 法, 邀请 15 位行业专家对燃气管线安 全风险可能性和后果严重性指标的重 要性进行打分, 并计算出各指标权 重, 结果如表 1 所示。 
表 1 燃气管线风险指标及权重

\begin{tabular}{|c|c|c|}
\hline 一级指标 & 二级指标 & 权重 \\
\hline \multirow{4}{*}{ 自身特征 } & $\begin{array}{c}\text { 管道材质及敷设 } \\
\text { 方式 }\end{array}$ & 0.0319 \\
\hline & 最小埋地深度 & 0.0933 \\
\hline & 管道年限 & 0.0651 \\
\hline & 历史发生概率 & 0.0647 \\
\hline \multirow{4}{*}{ 环境因素 } & $\begin{array}{c}\text { 燃气管道沿线地 } \\
\text { 区等级 }\end{array}$ & 0.06805 \\
\hline & 防火距离 & 0.08285 \\
\hline & 地理位置 & 0.041 \\
\hline & 土壤环境 & 0.05305 \\
\hline \multirow{3}{*}{$\begin{array}{l}\text { 安全基础 } \\
\text { 管理 }\end{array}$} & 安全生产责任制 & 0.04255 \\
\hline & 规章制度 & 0.0465 \\
\hline & 安全档案记录 & 0.03935 \\
\hline \multirow{5}{*}{$\begin{array}{l}\text { 安全现场 } \\
\text { 管理 }\end{array}$} & 警示标志 & 0.0203 \\
\hline & 管道腐蚀 & 0.0408 \\
\hline & 第三方活动 & 0.04685 \\
\hline & 沿线巡检 & 0.06605 \\
\hline & 运行控制 & 0.052 \\
\hline \multirow{3}{*}{ 人的因素 } & 管理人员 & 0.07065 \\
\hline & 一线员工 & 0.05025 \\
\hline & 附近居民 & 0.02475 \\
\hline
\end{tabular}

\section{2 后果指标权重的确定}

参照肯特法指标体系中对于事故 后果指标权重的确定方法, 对于处于 相同城区的门站、管线和小区，周边 设施和环境情况基本相同, 可以采用 相同的权重进行风险评估。指标体系 及权重如表 2 所示。
表 2 燃气风险后果指标及权重

\begin{tabular}{|c|c|c|}
\hline 一级指标 & 二级指标 & 权重 \\
\hline \multirow{4}{*}{ 泄露危害 } & 介质危险性 & 0.1667 \\
\cline { 2 - 3 } & 环境危险性 & 0.1667 \\
\cline { 2 - 3 } 事故影响 & 压力级别 & 0.1667 \\
\hline & 人口密度 & 0.0833 \\
\cline { 2 - 3 } & 财产分布 & 0.0833 \\
\cline { 2 - 3 } & 周边敏感目标影响 & 0.0833 \\
\cline { 2 - 3 } & 基设施破坏或中 & 0.0833 \\
\cline { 2 - 3 } & 断 & 0.0833 \\
\cline { 2 - 3 } & 舆论 & 0.0833 \\
\hline
\end{tabular}

\section{5 结论}

1) 以城市燃气管线为研究对象, 从固有风险和动态风险的分类以及 “人-物-环-管” 系统思想出发, 建立 了燃气风险可能性指标体系; 在借鉴 国内外经验的基础上, 建立了后果严 重性指标体系。

2）采用专家打分法和层次分析法 确定了各指标的权重。为燃气管线风 险评估分级工作奠定了基础。

\section{参考文献}

[1] 汪定怡,吕学珍.城市燃气输配管道 风险评价指数体系的建立 $[\mathrm{J}]$.城市 公用事业,2005,(06):36-39+48.

[2] 于京春.城镇燃气管道事故后果严 重度分析及评分[A].Proceedings of 2010 (Shenyang) International Colloquium on Safety Science and Technology[C]. Northeastern University（东北大学）,2010:4.

[3] 京安发.[2017]6号 北京市安全风险 管理实施办法（试行）[S].北京： 北京市安全生产委员会，2017.

[4] 韩朱昒.城市燃气管网风险评估方 法研究[D].清华大学,2010. 
[5] 于京春, 宋海宁, 王湘宁, 等. 城镇燃 气管道风险综合评价方法的选择 [J].煤气与热力,2010,30(09):22-25.

[6] 朱伟,翁文国,刘克会.城市地下管线 运行安全风险评估 $[\mathrm{M}]$. 北京，科 学出版社: 217-218.

[7] 易高翔.北京市危险化学品企业安 全生产风险评估分级研究 [J].中国 安全生产科学技术, 2010 (12) : 93-97.

[8] MARKOWSKI A S, MANNAN M S.Fuzzy logic for piping risk assessment[J].Loss Prevention in the Process Industries. 2009,(22):921927.

[9] CAGNO E, CARON F, MANCINI $\mathrm{M}$, et al. Using AHP in determining the prior distributions on gas pipeline failures in a robust Bayesian approach[J].Reliability Engineering and System Safety. 2000, 67:275-284.

[10] HAWDON DAVID. Efficiency, performance, and regulation of the international gas industry-a bootstrap DEA approach[M].Energy Policy.2003, (31): 1167-1178.

[11] 何倩卉,宋守信,顾一波等.人员密集 场所安全标识有效性实例评估 $[\mathrm{J}]$. 中国安全生产科学技术, 2015 (09):132-137. 